\title{
Endogenous $\mathrm{LXA}_{4}$ Circuits Are Determinants of Pathological Angiogenesis in Response to Chronic
} Injury

Alexander J. Leedom, Aaron B. Sullivan, Baiyan Dong, Denise Lau, and Karsten Gronert

From the Vision Science Program, School of Optometry, University of California, Berkeley, California

Inflammation and angiogenesis are intimately linked, and their dysregulation leads to pathological angiogenesis in human diseases. 15-lipoxygenase (15-LOX) and lipoxin $A_{4}$ receptors (ALX) constitute a $L X A_{4}$ circuit that is a key feature of inflammatory resolution. LXA $_{4}$ analogs have been shown to regulate vascular endothelial growth factor (VEGF)-A-induced angiogenic response in vitro. 15-LOX and ALX are highly expressed in the avascular and immune-privileged cornea. However, the role of this endogenous $\operatorname{LXA}_{4}$ circuit in pathological neovascularization has not been determined. We report that suture-induced chronic injury in the cornea triggered polymorphonuclear leukocytes (PMN) infiltration, pathological neovascularization, and up-regulation of mediators of inflammatory angiogenesis, namely VEGF-A and the VEGF-3 receptor (FLT4). Up-regulation of the VEGF circuit and neovascularization correlated with selective changes in both 15-LOX (Alox15) and ALX (Fprrs2) expression and a temporally defined increase in basal 15-LOX activity. More importantly, genetic deletion of 15-LOX or 5-LOX, key and obligatory enzymes in the formation of $\operatorname{LXA}_{4}$, respectively, led to exacerbated inflammatory neovascularization coincident with increased VEGF-A and FLT4 expression. Direct topical treatment with $\mathbf{L X A _ { 4 }}$, but not its metabolic precursor 15-hydroxyeicosatetraenoic acid, reduced expression of VEGF-A and FLT4 and inflammatory angiogenesis and rescued 15-LOX knockout mice from exacerbated angiogenesis. In summary, our findings and the prominent expression of 15-LOX and ALX in epithelial cells and macrophages place the $\mathbf{L X A}_{4}$ circuit as an endogenous regulator of pathological angiogenesis. (Am J Pathol 2010, 176:74-84; DOI: 10.2353/ajpath.2010.090678)
Formation of a new functional microvasculature, neovascularization, is a fundamental response to ischemia and a salient feature of wound healing. The primary function of newly formed blood vessels is to increase tissue oxygen tension and delivery of essential nutrients and effector cells to restore normal function. However, aberrant neovascularization is a hallmark feature of chronic inflammation and is associated with numerous pathological conditions that include diabetic retinopathy, Crohn's Disease, atherosclerosis, and cancer. ${ }^{1-3}$

The growth of microvessels from existing vessels, angiogenesis, is tightly controlled by a range of angiogenic factors and inhibitors; a circuit that is highly evolved in avascular tissues such as the cornea. The vascular endothelial growth factor (VEGF) family of angiogenic factors and their receptors are key mediators of this process, which has led to the recent development and clinical use of anti-VEGF strategies for the treatment of pathological neovascularization in the retina, colon cancer, and lung cancer. ${ }^{2-5}$ Many insights into the endogenous role of the VEGF network have been gained by using the cornea, 5,6 which maintains an immune-privileged and avascular state despite expression of VEGF-A and its immediate proximity to the vasculature. ${ }^{7}$ Specifically, recent findings have demonstrated that avascularity of the cornea requires expression of a soluble VEGF receptor-1 (sFLT1), which traps VEGF-A. ${ }^{8}$ In addition, the receptor for VEGFC/VEGF-D, namely VEGF receptor-3 (VEGFR-3, FLT4), is a critical regulator of inflammatory neovascularization. ${ }^{9-11}$ FLT4 is of special of interest because its essential expression during development becomes restricted primarily to lymph vessels and activation of this endothelial receptor is a critical step in initiating lymphangiogenesis. However, FLT4 expression is also up-regulated in microvessels of tumors and wounds, and in macrophages and in addition is constitutively expressed in

Supported in part by grants from the National Eye Institute EY016136 and P30EY003176.

Accepted for publication September 22, 2009.

Address reprint requests to Karsten Gronert, Ph.D., University of California, Berkeley, School of Optometry and Vision Science Program, 594 Minor Hall, MC 2020, Berkeley, CA 94720-2020. E-mail: kgronert@berkeley.edu. 
corneal epithelial cells. ${ }^{3,10-13}$ A recent report demonstrates that FLT4 is highly expressed in angiogenic sprouts and is a critical regulator of sustained hemeangiogenesis, ${ }^{12}$ which underscores the potential key role of this receptor in pathological neovascularization.

Inflammation is intimately associated with neovascularization especially during wound healing and ischemic injury. Lipid autacoids are some of the earliest signals that are released in response to injury or insult. In this regard, the 15-lipoxygenase pathway ${ }^{14,15}$ is of interest as it is one of the most inducible genes in macrophages and highly expressed in mucosal and corneal epithelial cells. Macrophages and epithelial cells are important regulators of angiogenesis, especially in avascular tissue such as the cornea. 3,10,16 Macrophages have a central and well-documented role in angiogenesis, especially in tumors and inflammatory neovascularization. In the cornea, a wellestablished model tissue for studying inflammatory neovascularization, VEGF-A recruits macrophages, the major cell type to generate VEGF, which drives inflammatory heme and lymphangiogenesis. Corneal epithelial cells constitutively express the receptor for VEGF-CNEGF-D (ie, FLT4), which has been proposed as a critical pathway for regulating inflammatory neovascularization. ${ }^{10}$

Human 15-LOX (ALOX15 and ALOX15B) generate 15S-hydroxyeicosatetraenoic acid (HETE) and mouse 12/15-LOX (Alox15) generates 15S-HETE and 12S-HETE from arachidonic acid. 15-HETE and 12-HETE have been shown to induce proliferation, migration, and tube formation in endothelial cells. ${ }^{17}$ More importantly, $15-$ HETE is a key intermediate in the formation of the well-studied antiinflammatory mediator lipoxin $\mathrm{A}_{4}\left(\mathrm{LXA}_{4}\right)$ that is generated via the rate-limiting enzyme 5-lipoxygenase (5-LOX). A body of work ${ }^{18-24}$ has established that the anti-inflammatory actions, which are associated with the up-regulation of 15-LOX and/or 15S-HETE formation are mediated by $L_{X} A_{4}$ and its G-protein coupled receptor $A L X$. Recent reports have demonstrated that stable analogs of $L X A_{4}$ inhibit VEGF induced angiogenic responses in endothelial cells. ${ }^{25-27}$ These metabolically stable analogs are mimetics of aspirin-triggered $L X A_{4}$, an endogenous isomer whose synthesis can be triggered by aspirin-acetylated cyclooxygenase-2 rather than 15-LOX. This 15-epiisomer of $\mathrm{LXA}_{4}$ resists metabolic inactivation and mediates it bioactions, like $L X A_{4}$, via the $A L X$ receptor. The intimate link between inflammation and angiogenesis and the ability of $\mathrm{LXA}_{4}{ }^{28}$ and analogs of 15-epi $\mathrm{LXA}_{4}{ }^{25-27}$ to inhibit VEGF-A induced angiogenic responses in vitro points toward a potential role of endogenous $L X A_{4}$ circuits in pathological angiogenesis. However, the endogenous role of 15-LOX in the regulation of angiogenesis remains controversial. Reports have demonstrated that the enzyme or its products promote or inhibit angiogenic responses in in vitro studies. ${ }^{29-32}$ More importantly, the in vivo role of the 15-LOX pathway or the LXA 4 circuit in pathological neovascularization remains to be clearly defined. To this end, we assessed the role the 15-LOX pathway and $\mathrm{LXA}_{4}$ circuit in chronic injury-induced inflammatory neovascularization.

Here, we report that inflammatory neovascularization and up-regulation of the VEGF circuit correlate with changes in both 15-LOX (Alox15) and $L X A_{4}$ receptor (ALX) expression and temporally defined 15-LOX activity. More importantly, genetic deletion of 15-LOX or 5-LOX, key enzymes in the formation of $L X A_{4}$, led to amplified neovascularization and expression of VEGF-A and FLT4 in the avascular cornea during chronic injury. $L X A_{4}$, but not 15S-HETE, attenuated expression of VEGF-A and FLT4 and the angiogenic response, which provides evidence that selective autacoids from the prominent 15LOX pathway have an endogenous role in limiting pathological neovascularization.

\section{Materials and Methods}

\section{Animals}

12/15-lipoxygenase (Alox15) and 5-lipoxygenase (Alox5) deficient mice (6 to 10 weeks, female) were purchased from Jackson Laboratory (Bar Harbor, ME). These Jax Gemm strains have a targeted mutation in 12/15-LOX or in 5-LOX that is in a background C57BI/6J inbred strain. These mice do not express a functional "leukocyte-type" 12/15-LOX (Alox15) or 5-LOX (Alox5). . 33,34 Age and gender-matched congenic C57BI/6J stock 000664 mice (6 to 10 weeks, female) were used as controls. Mice were maintained on a 12-hour day/night cycle and fed ad libitum a standard diet (Rat/Mouse diet LM-485, Harlan Tekland, Madison, WI).

\section{Corneal Neovascularization and Treatment}

All animal studies have been approved by the University of California, Berkeley in accordance with the NIH Guide for the Care and Use of Laboratory Animals and in strict accord with the ARVO Statement for the Use of Animals in Ophthalmic and Vision Research. Mice were anesthetized with ketamine $(50 \mathrm{mg} / \mathrm{kg})$ and xylazine $(20 \mathrm{mg} / \mathrm{kg})$ intraperitoneally and a drop of tetracaine-HCL $0.5 \%$ was applied to the eye to deliver local corneal anesthesia before injury. A single sterile 8.0 silk suture was placed intrastromally extending over the corneal apex, without disrupting the iris. Selected mice were treated topically t.i.d. with $\mathrm{LXA}_{4}$ or 15S-HETE (Cayman Chemical, Ann Arbor, MI), or sterile saline alone (PBS, ph 7.4) for two or seven days. Ethanol from the LXA 4 and 15S-HETE solutions were rapidly removed under gentle stream of nitrogen and autacoids immediately resuspended in sterile PBS and applied to the eye ( $5 \mu$ ldrop, t.i.d.). Eyes were enucleated at the respective time points under a stereo-microscope and corneas carefully dissected on ice to remove the limbus area and all noncorneal tissue. Isolated corneas were either snap frozen for RNA or lipidomic analyses, or immediately processed for immunohistochemistry.

\section{Assessment of Neovascularization and Inflammation}

Isolated corneas were rinsed in PBS, fixed in acetone $(100 \%)$ for 30 minutes, blocked in $2 \%$ bovine serum 
albumin/PBS solution and incubated in PBS containing fluorescein isothiocyanate-conjugated CD31/PECAM-1 overnight (Santa Cruz Biotechnology, Santa Cruz, CA; 1:100). Flatmounts were prepared by sectioning the cornea and fixing them to slides. The images were taken with a Zeiss Axiophot laser scanning confocal microscope and neovascularization was quantified by manually tracing the length of all vessels using Image Pro-Express software (Cyber Media) and was expressed as total pixels. Corneal flatmounts from 5-LOX KO mice and their matched congenic wild-type controls were taken with a Zeiss Axioplan 2 microscope equipped with a Ludl motorized stage and $z$ focus. Mosaic images were taken with a AxioCam MR camera and compiled using MosaiX and Zeiss AxioVision 4.5 software.

\section{Myeloperoxidase Activity}

Myeloperoxidase (MPO) activity, an index of tissue leukocyte infiltration, was measured 48 hours and 7 days post injury. ${ }^{35,36}$ In brief, corneas (1 cornea/data point) were homogenized with a hand held tissue grinder in 450 $\mu \mathrm{l}$ of $50 \mathrm{mmol} / \mathrm{L}$ potassium phosphate buffer containing $0.5 \%$ hexadecyltrimethylammonium bromide $(\mathrm{pH} 6.0)$. This was followed by sonication, freeze-thaw three times and a second sonication. The homogenates were then centrifuged and supernatants collected. MPO activity in supernatants was measured by spectrophotometry using o-dianisidine dihydrochloride oxidation as a colorimetric indicator. Calibration curves for MPO activities were established with PMN collected from 12 hours zymosan A-induced peritonitis exudates in mice.

\section{Gene and Protein Expression}

RNA from mouse corneas was isolated using RNA Easy Mini Kit (Qiagen Sciences, Maryland). RNA integrity was verified using agarose gel electrophoresis and quantified by spectrophotometry. RNA was reverse transcribed using a High-Capacity cDNA Kit (Applied Biosystems, Foster City, $\mathrm{CA})$. Heme oxygenase (HO)-1 was amplified using 5'-GATAGAGCGCAACAAGCAGAA-3' and 3'-CAGTGAGGCCCATACCAGAA-5'; VEGFA 5'-TCACCAAAGCCAGCACATAGGAGA-3' and 3'-TTCGTTTAACTCAAGCTGCCTCGC-5'; Fprl1 5'-CATTTGGTTGGTTCATGTGCAA-3' and 3'-AATACAGCGGTCCAGTGCAAT-5'; Fpr-rs2 5'-GCCAGG ACTTTCGTGGAGAGAT-3' and 3'-GATGAACTGGTGCTTGAATCACT-5'; VEGF-R3 (FLT-4) 5'-CTGGCAAATGGTTACTCCATGA-3' and 3'-ACAACCCGTGTGTCTTCACTG-5'; 12/15 LOX (Alox15) 5'-GCGACGCTGCCCAATCCTAATC-3' and 3'-ATATGGCCACGCTGTTTTCTACC-5';

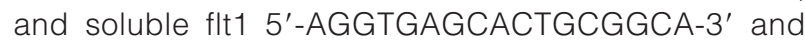
3'-ATGAGTCCTTTAATGTTTGAC-5'. Nucleotide primers were selected from the Harvard Primer Bank (pga.mgh. harvard. edu/primerbank) and verified by the NIH GenBank database or have recently been reported. ${ }^{35-39}$ Real-time PCR was performed using Fast SYBR Green Master Mix (Applied Biosystems) with a Step One Plus QPCR system (Applied Biosystems). Amplifications were run in duplicates and efficiencies for each primer pair were established.
Comparative quantification of gene expression was performed by Step One software (Applied Biosystems) using the $\Delta \Delta \mathrm{CT}$ method. Expression of all genes is referenced to a positive mRNA control that was generated by pooling mRNA from C57BI/6J mouse spleen and kidney.

\section{Lipid Mediator Lipidomics}

For endogenous lipid autacoid analysis, corneas were homogenized with a hand-held tissue grinder in 66\% methanol $\left(4^{\circ} \mathrm{C}\right)$. The methanol contained deuterated internal standards, prostaglandin (PG) $E_{2}-d_{4}, 15(S)$ - HETE$\mathrm{d}_{8}$, and leukotriene $\mathrm{B}_{4}\left(\mathrm{LTB}_{4}\right)-\mathrm{d}_{4}(400 \mathrm{pg} / \mathrm{each})$, to calculate the recovery of prostanoids or mono-hydroxy- and dihydroxy-containing fatty acids. Lipid autacoids were extracted by solid phase using Accubond ODS-C18 cartridges (Agilent Technologies, Santa Clara, CA) ${ }^{40}$ and the average extraction recovery of our class specific deuterated internal standard was $81 \%$ for $\mathrm{PGE}_{2}-\mathrm{d}_{4}, 60 \%$ for $\mathrm{LTB}_{4}-\mathrm{d}_{4}$, and $63 \%$ for $15-\mathrm{HETE}-\mathrm{d}_{8}$. Eicosanoids were identified and quantified by liquid chromatography (LC)/ mass spectrometry (MS)/MS-based lipidomics. ${ }^{37,41-45}$ In brief, extracted samples were analyzed by a triple quadruple linear ion trap LC/MS/MS system (MDS SCIEX 3200 QTRAP) equipped with a LUNA C18-2 minibore column using a mobile phase (methanol:water:acetate, 65:35:0.02, v:v:v) with a $0.50 \mathrm{ml} /$ flow rate. MS/MS analyses were performed in negative ion mode and prominent fatty acid metabolites were quantified by multiple reaction monitoring (MRM mode) using established transitions ${ }^{37,41,42,44,45}$ for $\mathrm{PGE}_{2} \quad(351 \rightarrow 271, \quad 351 \rightarrow 189$ $\mathrm{m} / \mathrm{z})$, thromboxane $\mathrm{B}_{2}(369 \rightarrow 169 \mathrm{~m} / \mathrm{z}), \mathrm{PGF}_{2} \alpha(353 \rightarrow 193$ $\mathrm{m} / \mathrm{z}), \mathrm{PGD}_{2}(351 \rightarrow 271 \mathrm{~m} / \mathrm{z}), 5$-HETE $(319 \rightarrow 115 \mathrm{~m} / \mathrm{z}), 15-$ HETE $(319 \rightarrow 175 \mathrm{~m} / \mathrm{z}), 12$-HETE $(319 \rightarrow 179 \mathrm{~m} / \mathrm{z}), 5,12$ $\mathrm{DiHETE} / L T B_{4}(335 \rightarrow 195 \mathrm{~m} / \mathrm{z}), \mathrm{LXA}_{4}(351 \rightarrow 115 \mathrm{~m} / \mathrm{z})$, $\mathrm{PGE}_{2}$-d4 $(335 \rightarrow 275 \mathrm{~m} / \mathrm{z}), \mathrm{LTB}_{4}$-d4 $(339 \rightarrow 197 \mathrm{~m} / \mathrm{z})$, and $15-$ HETE-d8 $(327 \rightarrow 182 \mathrm{~m} / \mathrm{z})$. Calibration curves ( 1 to $1000 \mathrm{pg}$ ) and specific LC retention times for each compound were established with synthetic standards (Cayman Chemical, Ann Arbor, MI). Structures were confirmed for selected autacoids by MS/MS analyses using enhanced product ion mode with appropriate selection of the parent ion in quadrupole 1.

\section{Statistics}

All data are expressed as mean \pm SEM unless otherwise indicated. Student's $t$-test was used to evaluate the significance of differences between two groups and multiple comparisons were performed by regression analysis and one-way analysis of variance. $P$ values of less than 0.05 were considered significant.

\section{Results}

The cornea in mice and humans is avascular and in general devoid of leukocytes; hence, it is an ideal tissue to study inflammatory neovascularization. Neovascularization is a fundamental response to severe corneal injury 

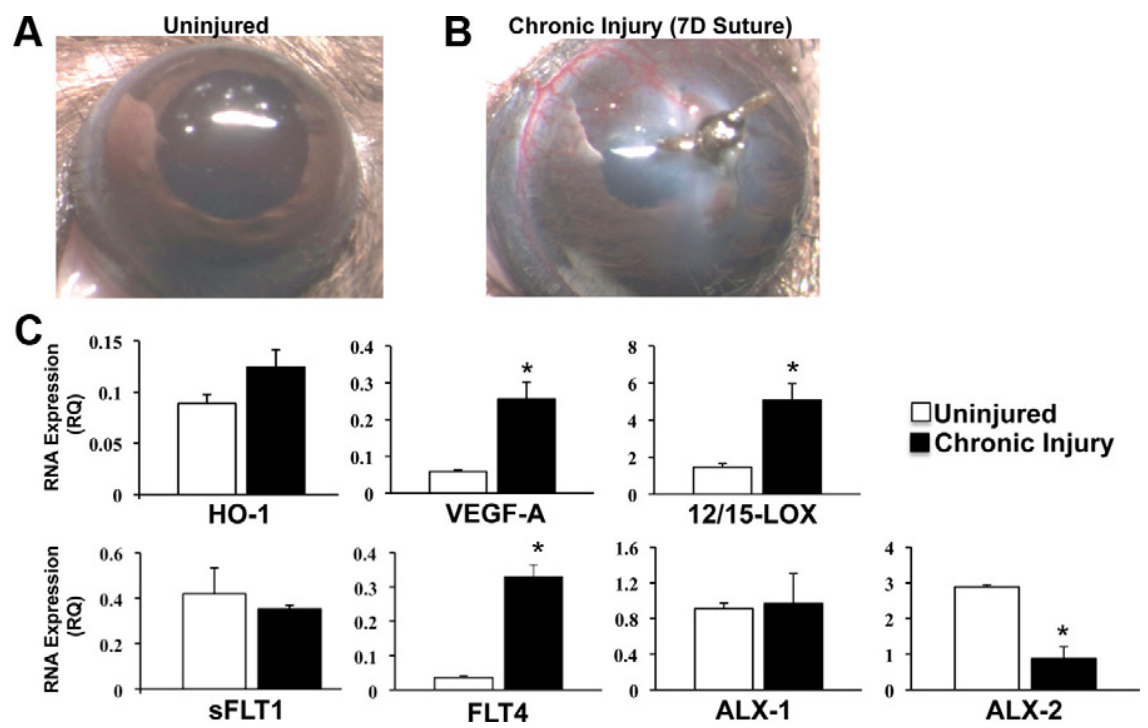

Figure 1. Inflammatory neovascularization differentially regulates expression of the LXA circuit. A: Representative images of an uninjured cornea. B: An 8.0 silk suture was placed intrastromally in female C57/BL6 mice. Image of cornea with neovascularization after 7 days of chronic injury. C: mRNA expression of selected genes was quantified by real-time PCR analyses in corneas after 7 days of chronic injury for heme oxygenase-1 (HO-1), vascular endothelial growth factor A (VEGF-A), soluble VEGF receptor-1 (sFLT1), VEGF receptor-3 (FLT4), 12 and /15 LOX (Alox15), and after 48 hours for ALXR-1 (Fprl1) and ALXR-2 (Fpr-rs2). mRNA expression was compared with matched untreated corneas and is expressed as relative quantity (RQ) compared with a mouse positive mRNA control $\left(n=4,{ }^{*} P<0.05\right)$ using the $\Delta \Delta \mathrm{CT}$ method and $\beta$-actin as a reference gene. or infection such as microbial keratitis and chemical burns and a key feature of the pathogenesis. We selected the well-established corneal suture model as it induces robust and quantifiable neovascularization as a consequence of chronic injury and irritation. ${ }^{10,11,16}$ Consistent with the model, the silk suture induced robust formation of new blood vessels originating from the vascular border of the cornea (limbus) that become visible by day 4 and are pronounced by day 7 (Figure 1, A-B).

Due to the small tissue size of the mouse cornea, we selected real-time PCR to quantify mRNA expression of key mediator of angiogenesis and pathways that limit the sequelae of corneal injury (Figure $1 \mathrm{C}$ ). Chronic injury led to a significant 4.3-fold increase in mRNA levels of VEGF-A (injured $=0.256 \pm 0.046$ relative quantity [RQ] versus uninjured $=0.059 \pm 0.005 R Q, n=4)$ and $a$ significant 9.2 fold increase in the receptor FLT4 (injured $0.330 \pm 0.034 R Q$ versus uninjured $=0.036 \pm 0.004 R Q$, $n=4)$. In contrast, expression of the soluble FLT1 receptor (sFLT1), which traps VEGF-A in the cornea, did not change in response to injury. Consistent with the temporally defined induction of $\mathrm{HO}-1,{ }^{46}$ an early response and cytoprotective gene, levels of $\mathrm{HO}-1$ were no longer significantly elevated after 7 days of chronic injury compared with basal expression. Chronic injury differentially altered the expression of the resident $L X A_{4}$ biosynthetic pathway and its receptor (Figure $1 \mathrm{C}$ ), which are expressed in both recruited leukocyte and resident corneal epithelial cells. ${ }^{15,36}$ Specifically, both $A L X$ receptors (Fprl1 and Fprs2) were expressed in the uninjured cornea of C57BI/6J. Expression of ALX1 (Fprl1) did not change after 2 days of chronic injury. However, expression of ALX2 (Fprs2) decreased by $70 \%$ (injured $=2.89 \pm 0.61$ $R Q$ versus uninjured $=0.873 \pm 0.559 R Q, n=4$ ) despite the fact that 2 days is the initial phase of PMN infiltration, a cell type that expresses both $\mathrm{ALX} 1$ and $\mathrm{ALX} 2 .{ }^{47}$ In sharp contrast mRNA levels for 12/15-LOX mRNA increased by 3.5 fold (injured $=5.07 \pm 0.90 R Q$ versus uninjured $=1.46 \pm 0.19 R Q, n=4$ ) as a consequence of 7-day chronic injury when directly compared with healthy corneas.

To assess if pathological angiogenesis was associated with temporally defined changes in endogenous lipid autacoid formation, we used LC/MS/MS-based lipidomics analyses, which demonstrated selective formation of LOX and cyclooxygenase-derived autacoids. Consistent with the time course of neovascularization and up-regulation of 12/15-LOX, endogenous levels of 15-HETE demonstrated a temporally defined increase from 33 pg/cornea in the uninjured cornea to a peak of $94 \mathrm{pg} / \mathrm{cornea}$ by day 4 (Figure 2; uninjured $=33 \pm 6$ pg/cornea versus injured $=94 \pm 10 \mathrm{pg} / \mathrm{cornea}, n=4$ ) coinciding with the first appearance of functional blood vessels. 15-HETE is a metabolic intermediate for the formation of $L X A_{4}$ in the cornea and thus a marker for the biosynthetic pathway. ${ }^{15}$ We were not able to consistently detect endogenous $\mathrm{LXA}_{4}$ formation in isolated single corneas of C57BI/6J female mice. However, endogenous $L_{X} A_{4}$ formation in the cornea has been reported in a different strain of mice (BALB/c, males) in a model of self-resolving abrasion injury ${ }^{36}$; these differences in corneal $L X A_{4}$ levels likely reflect differences in mouse strain, gender and injury model. Moreover, our lipidomic analysis did not measure tissue levels of $15-0 \times 0-L X A 4,{ }^{45}$ the primary endogenous metabolite of $L X A_{4}$, which may reflect a significant and established route of metabolic inactivation. Thus our measurements likely underestimated the corneal levels of $L X A_{4}$, especially during chronic inflammation.

12-HETE levels were higher in both the uninjured $(222 \pm 55 \mathrm{pg} / \mathrm{cornea}, n=4)$ and injured cornea by day $7(237 \pm 61 \mathrm{pg} / \mathrm{cornea}, n=4)$ compared with $15-\mathrm{HETE}$ levels, which reflects the expression of several distinct 12-LOX isozymes in the mouse cornea. ${ }^{15,36}$ Unlike 15HETE, levels of 12-HETE did not increase in response to chronic injury or parallel the time course of neovascularization. Consistent with previous reports, both the uninjured and injured cornea demonstrated 5-LOX activity, ${ }^{36}$ a key and rate-limiting enzyme in the metabolism of 15- 

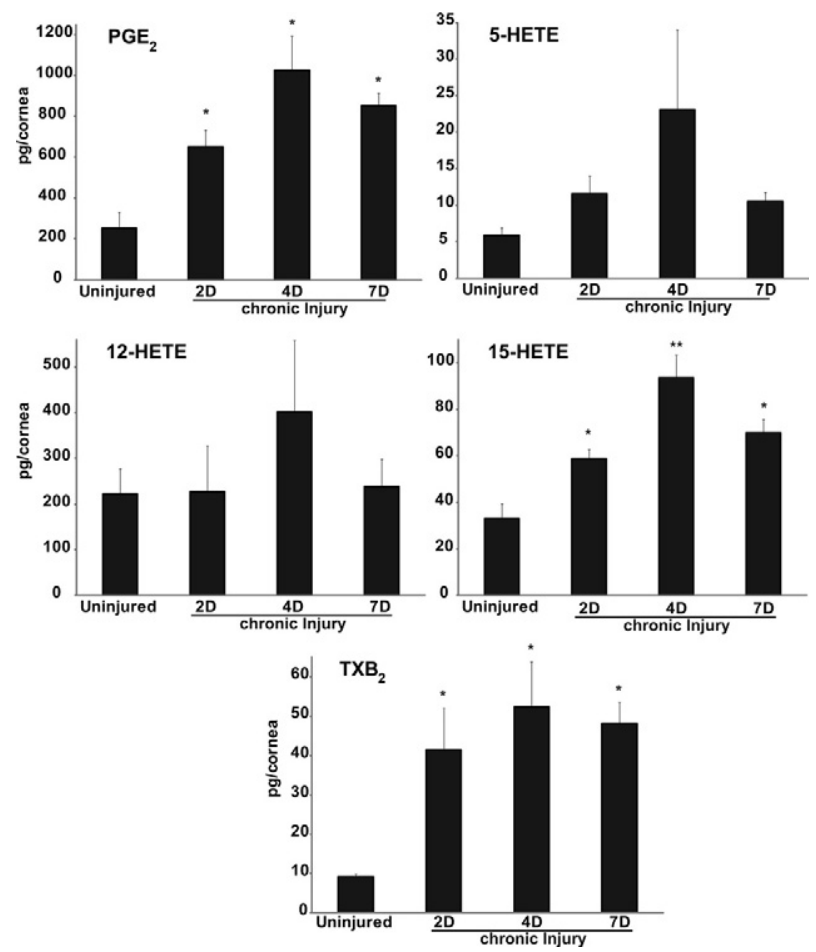

Figure 2. Inflammatory neovascularization is associated with the dynamic formation of select lipid autacoids. Endogenous lipid autacoids were quantified in corneas without injury and after 2, 4, and 7 days of chronic injury by MS based lipidomic analyses using triple quadrupole LC/MS/MS system (MDS SCIEX QTRAP 3200). Specific transition ions and multiple reaction monitoring was used to measure levels of $>20$ eicosanoids in a single mouse corneas. Significant levels of prostaglandin $\mathrm{E}_{2}\left(\mathrm{PGE}_{2}\right), 15$-hydroxyeicosatetraenoic acid (15-HETE), thromboxane $B_{2}$, 5-hydroxyeicosatetraenoic acid (5-HETE), and 12S- hydroxyeicosatetraenoic acid (12-HETE) were detected in injured and uninjured corneas $\left(n=4,{ }^{*} P<0.05\right.$ versus uninjured, ${ }^{* *} P<$ 0.05 versus $2 \mathrm{D})$.

HETE to $\mathrm{LXA}_{4} \cdot{ }^{47}$ 5-LOX activity (ie, 5-HETE formations) did not increase during the time course of chronic injury and consistent with a previous report ${ }^{36} \mathrm{LTB}_{4}$ formation was not detected in injured or uninjured corneas. In addition to 15-HETE, formation of the cyclooxygenase metabolites $\mathrm{PGE}_{2}$ and thromboxane $\mathrm{B}_{2}$ demonstrated a time dependent increase in response to chronic injury and their formation paralleled that of 15-HETE and neovascularization (Figure 2). PGE 2 was the most prominent eicosanoid in the inflamed and vascularized cornea, peaking at $1.1 \mathrm{ng} / \mathrm{cornea}$ ( $1030 \mathrm{pg} \pm 167, n=4$ ) by day 4 , which is consistent with its role as key mediator of inflammation and angiogenesis. ${ }^{33,48}$

To define the endogenous role of the 15-LOX in inflammatory neovascularization, we used the well-defined 12/ 15-LOX (Alox15) KO mice and matched congenic controls. In vivo deletion of 12/15-LOX, which is highly expressed in corneal epithelial cells and recruited leukocytes, ${ }^{36}$ correlated with a 2.8-fold (12/15-LOX KO = $5125 \pm 500$ PMN versus wild-type $=1770 \pm 1277$ PMN, $n=4$ ) increase in the number of PMN after 7 days of chronic injury (Figure 3A). These findings are consistent with the notion that 15-LOX is a central pathway for the formation of pro-resolving and anti-inflammatory autacoids, ${ }^{18,21,49}$ such as $\mathrm{LXA}_{4}$, in the cornea. ${ }^{18,21,36}$ 15-LOX activity (ie, 15-HETE formation) in the injured cornea of 12/15-LOX deficient mice was decreased by $60 \%$ (Figure $3 \mathrm{~B}$, wild-type $=59 \pm 4 \mathrm{pg} /$ cornea versus 12/15-LOX $\mathrm{KO}=23 \pm 9$, pg/cornea, $n=4$ ). The lack of complete ablation of 15-LOX activity in the Alox15 $\mathrm{KO}$ mice is in agreement with the fact that mice express multiple 12LOX isozymes in the cornea, ${ }^{15}$ which can contribute toward the overall endogenous 15-HETE formation. We have previously demonstrated that topical $L X A_{4}$, but not its metabolic intermediate 15-HETE, inhibits exacerbated inflammation in the cornea. ${ }^{35}$ In the current chronic injury model topical $\mathrm{LXA}_{4}$ (100 ng, t.i.d.) consistently inhibited PMN infiltration after 48 hours of chronic injury by $49 \%$, when directly compared with saline treatment alone (Figure $3 \mathrm{C}, \mathrm{LXA}_{4}=9523 \pm 3226 \mathrm{PMN} /$ cornea versus saline $=18,750 \pm 4417 \mathrm{PMN} /$ cornea).

Pathological neovascularization as a consequence of chronic injury (7 days) was markedly exacerbated in 12/15-LOX KO mice, which had a $180 \%$ increase in the total number of blood vessels, as compared with the matched congenic wild-type mice (Figure 4A, 12/15-LOX $\mathrm{KO}=52899 \pm 2477$ pixels versus wild-type $=19016 \pm$ 1490 pixels, $n=4$ ). Topical $\operatorname{LXA}_{4}$ (100 ng, 7 days, t.i.d.) consistently attenuated pathological neovascularization by $38 \%(11775 \pm 909$ pixels, $n=3)$ and was able to markedly reduce the exacerbated neovascularization by $45 \%$ in 12/15-LOX KO mice (28979 \pm 1448 pixels, $n=4)$, which have an impaired $\mathrm{LXA}_{4}$ biosynthetic pathway. ${ }^{36}$ Since $15 S-H E T E$ is a metabolic intermediate in the forma-
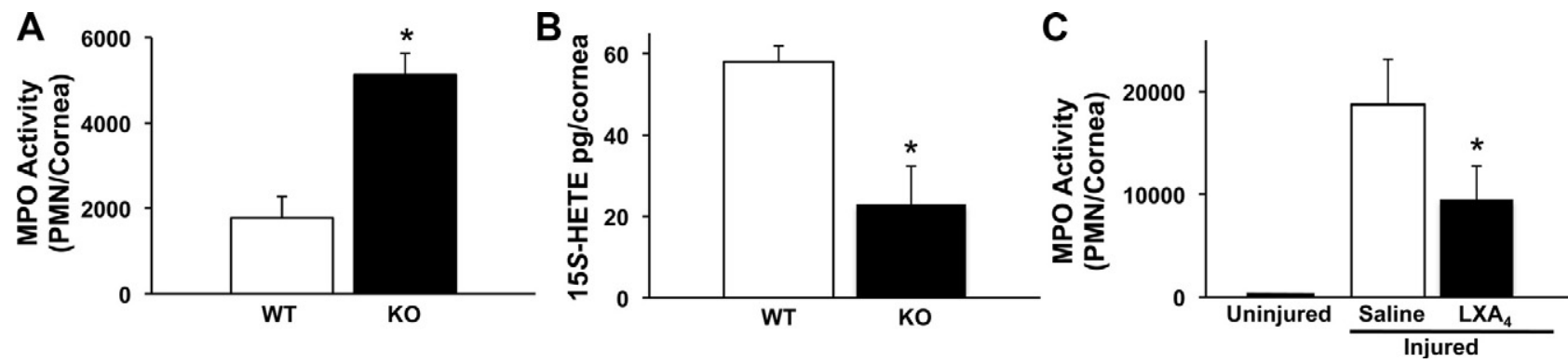

Figure 3. Deletion of a LXA 4 biosynthetic pathway or topical treatment with LXA regulates PMN recruitment to the injured cornea. A: PMN content of corneas from 12/15-LOX KO mice and matched congenic wild-type (wt) controls was assessed by measuring tissue MPO activity after 7 days of chronic injury $(n=4$, $P<0.02)$. A MPO calibration curve was established with inflammatory exudate peritoneal PMN and used to calculate relative tissue PMN numbers. B: 15 -HETE formation, a metabolic precursor for LXA 4 formation, was determined by LC/MS/MS-based lipidomic analyses after 4 days of chronic injury $\left(n=4 ;{ }^{*} P<0.05\right)$. C: Topical action of LXA 4 on PMN recruitment to the injured cornea was determined at 48 hours. Relative PMN numbers in uninjured corneas and injured corneas treated with either saline alone or $\mathrm{LXA}_{4}\left(100 \mathrm{ng}\right.$, t.i.d.) were assessed by measuring total tissue MPO activity $\left(n=4,{ }^{*} P<0.02\right)$. 

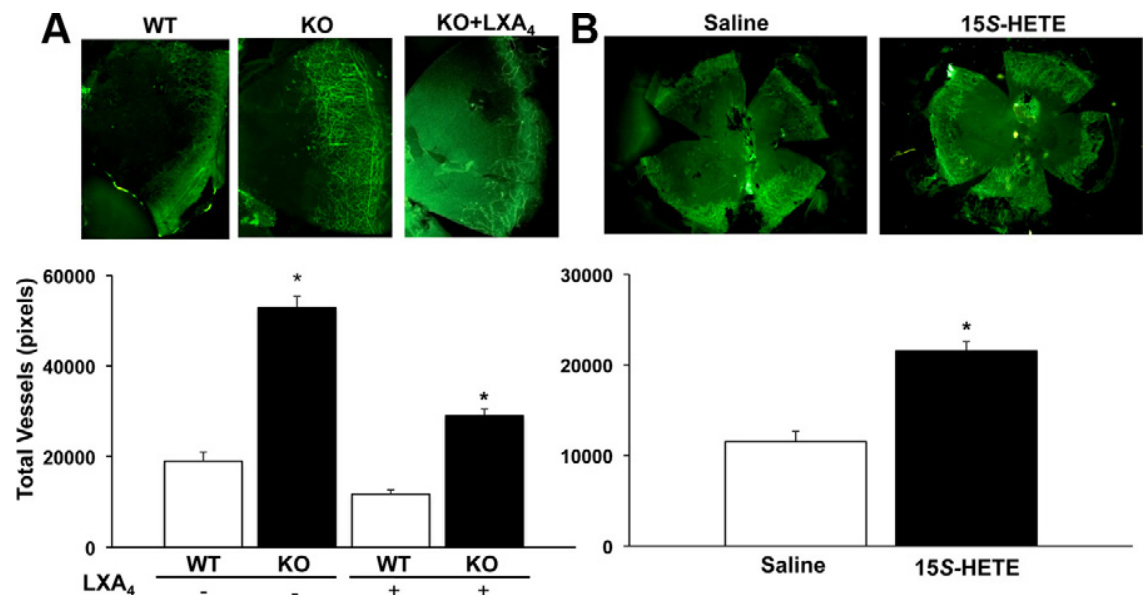

Figure 4. Topical $\mathrm{LXA}_{4}$ attenuates inflammatory neovascularization and inhibition of its biosynthetic pathway exacerbates pathological angiogenesis. A: Heme-angiogenesis in corneas with 7 days of chronic injury was assessed by immunohistochemistry using CD31 as a specific endothelial antigen. Corneas from 12/15-LOX KO or matched congenic wild-type (wt) mice treated with or without topical LXA 4 (100 ng, t.i.d., 7 days) were collected and incubated in PBS containing fluorescein isothiocyanate-conjugated CD31/PECAM-1 monoclonal antibody and analyzed using a Zeiss Axiophot laser scanning confocal microscope. Images show neovascularization of representative corneal quadrants. All $\mathrm{CD} 31^{+}$vessels were traced manually and are expressed as total pixels (Image Pro Express 6.0) $\left(n=3\right.$ to $\left.4 ;{ }^{*} P<0.05\right)$. B: Topical 15 -HETE exacerbates inflammatory neovascularization. Injured corneas were treated topically with either 15 S-HETE (100 ng, t.i.d.) or sterile saline for 7 days. Images show representative whole corneal flat mounts (left panel, saline treatment alone; right panel $15 \mathrm{~S}$-HETE treatment). Al $\mathrm{CD}_{31}{ }^{+}$vessels were traced manually and are expressed as total pixels $\left(n=4 ;{ }^{*} P<0.05\right)$. tion of $L X A_{4}$, we assessed if 15S-HETE shared the potent bioactions of topical $L X A_{4}$. Treatment with topical 15SHETE (100 ng, t.i.d., 7 days), contrary to $L X A_{4}$, markedly amplified pathological neovascularization by $87 \%$ (Figure $4 \mathrm{~B}, 15 \mathrm{~S}-\mathrm{HETE}=21516 \pm 1048$ pixels versus saline alone $=11497 \pm 1142$ pixels, $n=3$ ).

To obtain proof of concept for a role of endogenous $\mathrm{LXA}_{4}$ in pathological neovascularization, we used 5-LOX $\mathrm{KO}$ mice, which are $\mathrm{LXA}_{4}$ knockout mice ${ }^{49-51}$ since the mouse genome only contains one 5-LOX enzyme, the obligatory and rate-limiting enzyme for $L X A_{4}$ formation.

5-LOX is a well-studied and prominent enzyme in most leukocytes, especially PMN and macrophages. ${ }^{34}$ Recent reports have established expression and activity of this enzyme in uninjured and inflamed mouse corneas ${ }^{36}$ and RNA expression in bovine corneas and human corneal epithelium. ${ }^{52}$ Deletion of the $\mathrm{LXA}_{4}$ biosynthetic pathway in 5 -LOX KO mice was associated with a $148 \%$ increase in pathological neovascularization (Figure 5) when directly compared with matched congenic wild-type mice (5-LOX $\mathrm{KO}=164180 \pm 9072$ pixels versus wild-type $=66193 \pm$ 6122 pixels, $n=4)$. Taken together, in vivo deletion of two key biosynthetic pathways for formation of endogenous $\mathrm{LXA}_{4}$ in the cornea (ie, 15-LOX and 5-LOX) provides strong evidence for a key role of endogenous $L X A_{4}$ circuit as a key regulator of inflammatory neovascularization.

Real-time PCR analysis was used to assess the impact of impaired 12/15-LOX activity on endogenous pathways that are markers of inflammatory neovascularization and stress responses during the initial stage of the angiogenic response (48 hours). mRNA expression of key mediators of inflammatory angiogenesis was markedly amplified in 12/15-LOX KO mice when directly compared with matched congenic wild-type mice (Figure 6). In accordance with exacerbated neovascularization VEGF-A $(\mathrm{KO}=8.80 \pm 1.32$-fold versus wild-type $=4.60 \pm 0.64$ fold, $n=4)$, sFLT1 (KO = 7.79 \pm 1.64 -fold versus wildtype $=1.51 \pm 0.272$ fold, $n=4)$, and FLT4 (KO = 31.7 \pm 9.27 versus wild-type $=10.4 \pm 1.17$-fold, $n=4) \mathrm{mRNA}$ levels increased $91 \%, 413 \%$ and $210 \%$ in $12 / 15$-LOX KO mice, respectively. Up-regulation of $\mathrm{HO}-1$ and sFLT1 suggest a compensatory mechanism in this avascular and immune-privileged tissue to counter exacerbated neovascularization in the 12/15-LOX KO mice.

Recent reports have demonstrated that stable analogs of $\mathrm{LXA}_{4}$ inhibit VEGF-A-induced angiogenic responses in isolated endothelial cells $\mathrm{s}^{25,26,28}$ and the murine airpouch model $^{27}$ by inhibiting downstream signals of the VEGF-2 receptor (FLK1). In view of intimate and dynamic interactions of inflammatory and angiogenic pathways in physiological responses to injury, we assessed the in vivo actions of native $L X A_{4}$ on selected pathways that regulate
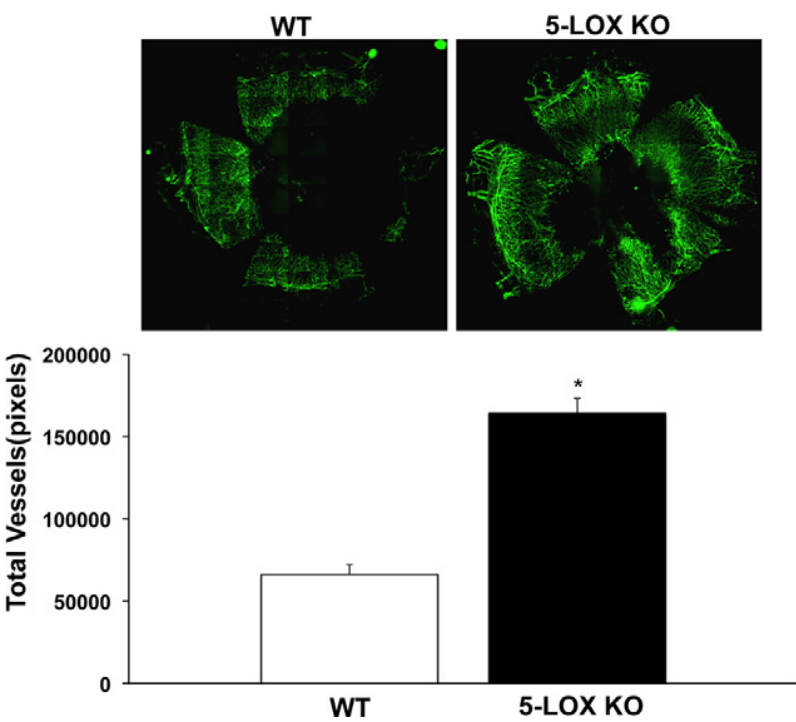

Figure 5. 5-LOX/LXA 4 KO mice have a phenotype of exacerbated neovas cularization in response to chronic injury. 5-LOX KO mice, which cannot generate $\mathrm{LXA}_{4}$, and their matched congenic wild-type (wt) controls were subjected to chronic suture injury for 7 days. Corneas were removed and pathological angiogenesis quantified by immunohistochemistry using a Zeiss Axioplan 2 microscope. Mosaic images were taken with a AxioCam MR camera and compiled using MosaiX and Zeiss AxioVision 4.5 software. Inset shows representative whole corneal flatmounts (left panel, wild-type; right panel, 5-LOX KO). Vessel density was documented and expressed as total pixels (Image Pro Express 6.0) $\left(n=4 ;{ }^{*} P<0.05\right)$. 

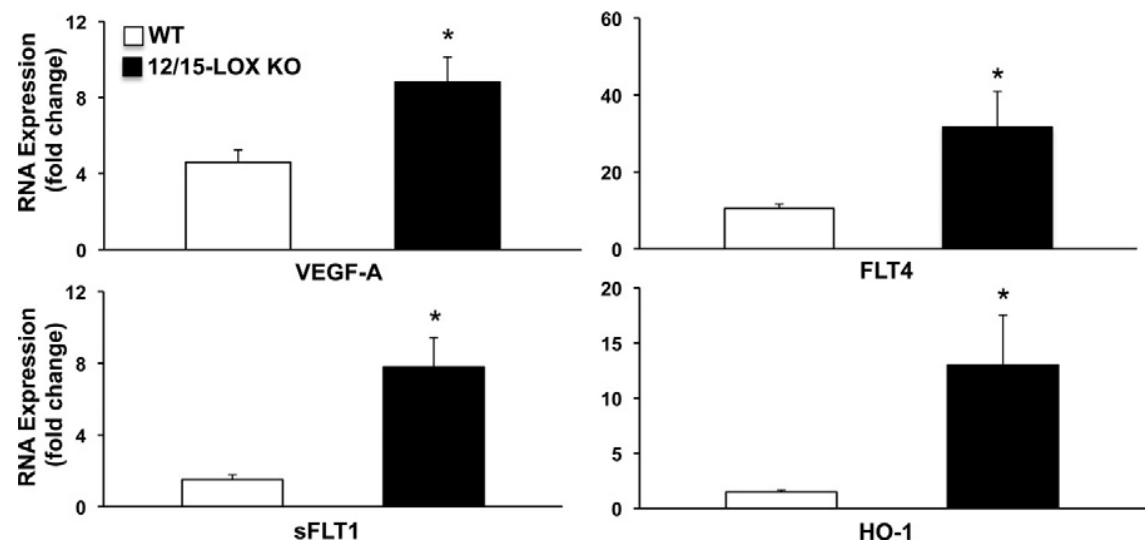

Figure 6. Deletion of 12/15 LOX up-regulates key regulators of inflammatory neovascularization. Corneas after 48 hours of chronic injury were collected from 12/15-LOX KO and matched congenic wild-type mice $(n=4)$. mRNA expression was quantified for HO-1, VEGF-A, sFLT1, and FLT4 using a Step One Plus QPCR system (Applied Biosystems). RNA expression for each gene was calculated using relative quantity (RQ) compared with a mouse positive mRNA control with the $\Delta \Delta$ CT method and $\beta$-actin as a reference gene. Data are expressed as fold change compared with the mouse positive mRNA control $\left(n=4,{ }^{*} P<0.05\right)$. the angiogenic and inflammatory responses to chronic injury in the cornea (Figure 7). A fundamental feature of exacerbated/aberrant inflammation, especially in the immune privileged cornea, is the up-regulation of protective pathways such as HO-1 and 12/15-LOX. ${ }^{36,38,46,53}$ Direct topical treatment with $\mathrm{LXA}_{4}(100 \mathrm{ng}$, t.i.d., Figure 7) significantly reduced levels of $\mathrm{HO}-1$ and $12 / 15-\mathrm{LOX}$ by 4.4 fold $\left(\mathrm{LXA}_{4}=0.010 \pm 0.002 \mathrm{RQ}\right.$ versus saline $=0.044 \pm$ $0.042 R Q, n=4)$ and 3.3 fold $\left(L_{X A}=0.015 \pm 0.02 R Q\right.$ versus saline $=0.050 \pm 0.02 R Q, n=4$ ), respectively. In accordance with the observation that exogenous amplification of the LXA4 circuit reduced expression of resident protective circuits in the injured cornea, topical $L X A_{4}$ also significantly reduced mRNA levels of VEGF-A and FLT4 by $66 \%\left(\mathrm{LXA}_{4}=0.120 \pm 0.024 \mathrm{RQ}\right.$ versus saline $=$ $0.358 \pm 0.001 R Q, n=4)$ and $80 \%(0.015 \pm 0.005 R Q$ versus $0.003 \pm 0.001 R Q$ ), respectively. $L X A_{4}$ mediates its established bioactions via the $A L X$ receptor, which is expressed predominantly in the epithelium of healthy
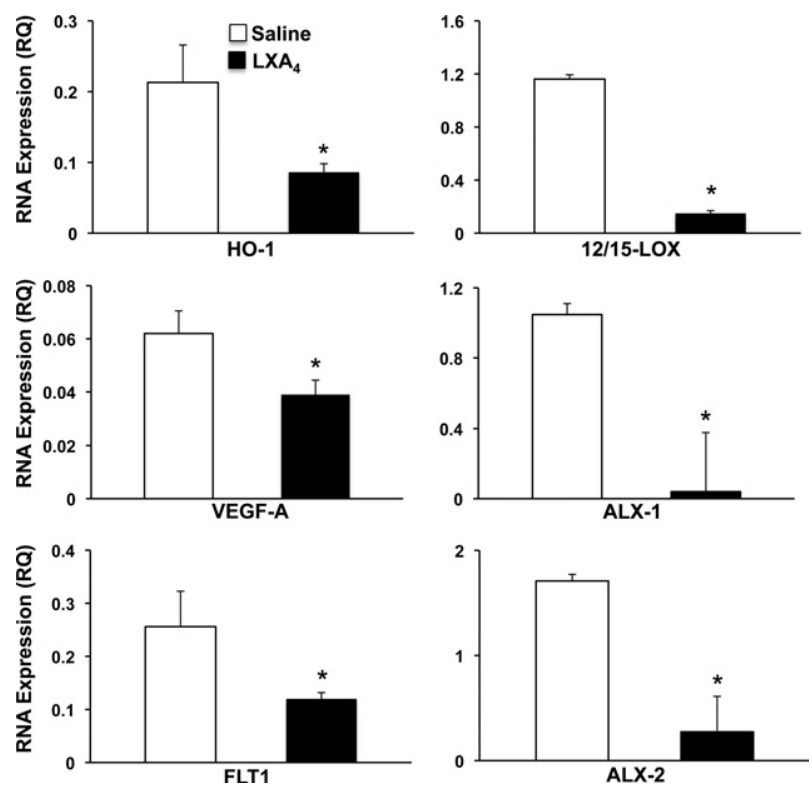

Figure 7. Direct topical treatment with $\mathrm{LXA}_{4}$ down-regulates expression of key regulators of inflammatory angiogenesis. After suture injury corneas were treated with either saline alone or $\mathrm{LXA}_{4}(100 \mathrm{ng}$, t.i.d.) for 48 hours. mRNA expression was quantified for HO-1, VEGF-A, FLT4, and both LXA 4 receptors (ALX-1, ALX-2) using a real-time PCR system. Relative expression was compared with a mouse positive mRNA control $\left(n=4,{ }^{*} P<0.05\right)$. corneas and recruited leukocytes. ${ }^{36,47}$ Direct corneal treatment with $L X A_{4}$ abrogated expression of both $L X A_{4}$ receptors (ALX-1, LXA $=0.040 \pm 0.018 R Q$ versus saline = $1.05 \pm 0.447 \mathrm{RQ} ; \mathrm{ALX}-2 \mathrm{LXA}_{4}=0.274 \pm 0.097$ $R Q$ versus saline $=1.710 \pm 0.678 R Q, n=3$ ) in the injured cornea suggesting a ligand-dependent negative feedback loop in this tissue. This response is distinct from the innate immune responses in the peritoneal cavity, ${ }^{54}$ where transgene expression of human $A L X$ in a positive feed forward loop increases endogenous $L X A_{4}$ formation by the inflammatory exudate.

\section{Discussion}

A coordinated and synergistic array of pro- and antiangiogenic signals regulates the multicellular process of angiogenesis that leads to the formation of functional blood and/or lymph vessel. ${ }^{3}$ Inflammation and angiogenesis are triggered, especially in response to injury and insult, by the same molecular events and in a reciprocal fashion these two fundamental responses sustain each other. Indeed, there is strong evidence for a close association or co-dependence between chronic inflammation and angiogenesis in several human diseases. ${ }^{2,3}$

An essential feature of acute inflammation is the resolution of leukocytes and restoration of normal tissue function. ${ }^{55}$ It is well established that dynamic lipid circuits, such as the $L X A_{4}$ circuit, have a pivotal role in the active resolution of normal and vital inflammatory responses. ${ }^{49,55-57}$ Hence, it stands to reason that resolution of heme- or lymphangiogenesis, like inflammation, is an active and highly coordinated process that is regulated by common or shared pathways. 12/15-lipoxygenase is a central biosynthetic pathway in mucosal tissues and the cornea for the formation of $\mathrm{LXA}_{4},{ }^{15}$ an eicosanoid that is formed in both humans and mice. ${ }^{49,55-57}$ In addition, 12/15-LOX is a key enzyme for the formation of $\omega-3$ polyunsaturated fatty acidderived mediators, namely protectins, resolvins, and maresins, ${ }^{36,58-61}$ which have demonstrated ant-inflammatory and anti-apoptotic and/or pro-resolving bioactions. These 15LOX products, namely protectins and resolvins, are formed in the eye. ${ }^{36,58,60,62}$ Hence, in addition to $L X A_{4}, 15-L O X$ can generate additional classes of potent anti-inflammatory mediators, which can contribute to the protective function of 
this enzyme in the eye. It is of particular interest that chronic injury of the cornea and pathological angiogenesis are associated with increased expression and functional activity of 12/15-LOX (Figure 1 and 2). More importantly, in vivo deletion of 12/15-LOX (Alox15) resulted in marked amplification of inflammatory neovascularization (Figures 3 and 4), which provides direct evidence that this prominent ocular enzyme ${ }^{15,58,60,63,64}$ has a key role in attenuating inflammatory neovascularization. The notion that 15-LOX is a protective pathway in acute inflammatory responses is supported by studies that demonstrate that in vivo transfection with human 15-LOX (ALOX15) provides functional protection against immune-mediated renal injury. ${ }^{65}$ Moreover, transgenic rabbits, ${ }^{54,66}$ which selectively express human ALOX15 in monocytes/macrophages and PMN, demonstrate functional protection against neutrophil-mediated tissue injury, microbial inflammation, and atherosclerosis.

The endogenous role of 15-LOX in angiogenesis is not well defined and has not been explored in models of inflammatory neovascularization. In vitro studies that either add 15S-HETE to microvascular endothelial cell lines $^{30,31}$ or express human 15-LOX (ALOX15) in rabbit skeletal muscle ${ }^{32}$ have led to conflicting conclusions, namely, that the 15-LOX pathway either induces angiogenic responses or inhibits VEGF-A induced angiogenesis, respectively. 15-lipoxygenase can initiate the potential formation of several distinct classes of lipid autacoids that have pleiotropic actions. Endogenous formation of two 15-LOX-derived products are firmly established in several animal models of inflammation and human tissue, namely 15 S-HETE and $\mathrm{LXA}_{4} \cdot{ }^{14,47,49,57} \mathrm{~A}$ body of work ${ }^{49,55,57,67,68}$ has established the endogenous formation of $\mathrm{LXA}_{4}$ and its role as a key mediator of inflammatory resolution. ${ }^{55,57}$ More importantly, unlike other 15-LOX metabolites, data from receptor transgenic mice and detailed structure-activity studies have established specific ALX receptors in humans (FPRL1) and mice (Fprl1 and Fpr-rs2) as a molecular mechanism for $\mathrm{LXA}_{4}$ 's protective in vivo actions. ${ }^{47}$

In accordance with our previous studies in male $\mathrm{BALB} / \mathrm{c}$ mice $^{36}$ and the original identification of ALX in human corneas, ${ }^{69}$ we detected basal expression of ALX-1 (Fprl1) in uninjured corneas of female C57BI/6J mice and were also able to detect expression of ALX-2 (Fpr-rs2). More importantly, our findings demonstrate that ALX-2 expression is markedly down-regulated as a consequence of chronic injury, which is coincident with pathological neovascularization. If reduced expression of ALX2 attenuates the protective actions of endogenous $\mathrm{LXA}_{4}$ and the mechanism for the dynamic regulation of the corneal ALX2 receptor remains to be determined and are of great interest. Our findings are in line with a recent report ${ }^{39}$ that confirmed expression of a $L X A_{4}$ receptor (Fprs-rs2) in the cornea of BALB/c mice. Also note, unlike this report, ${ }^{39}$ we detected formation of both $\mathrm{LXA}_{4}$ receptors in uninjured corneas and observed dynamic regulation of ALX-2, which may reflect differences in the sensitivity of analytical methods, mouse strain, and/or gender differences.

The rationale for focusing on the in vivo actions of $L X A_{4}$ and activation of the corneal ALX receptor ${ }^{36,70}$ as a likely
12/15-LOX induced circuit that attenuates inflammatory neovascularization was based on several independent lines of evidence: 1) the key observation that inflammatory neovascularization was associated with a specific decrease in one of the mouse $L_{X A_{4}}$ receptors (Fpr-rs2, Figure 1); 2) previous findings that demonstrate that corneal formation of $\mathrm{LXA}_{4}$ is attenuated in 12/15-LOX KO mice; ${ }^{36}$ and 3 ) reports that have demonstrated that stable mimetics of $\mathrm{LXA}_{4}$ inhibit VEGF-induced angiogenesis. ${ }^{25-27,39}$

More importantly, in vivo deletion of 5-LOX, which is the obligatory and rate-limiting enzyme for $\mathrm{LXA}_{4}$ forma$\operatorname{tion}^{47,49}$ led to pronounced amplification of neovascularization (Figure 6).

It is important to note that except for $\mathrm{LXA}_{4}$, other 5-LOX products such as leukotrienes are potent and well-established pro-inflammatory mediators in both humans and mice. ${ }^{33}$ Inflammation is an essential feature of injury-induced neovascularization and amplifies the angiogenic response in the cornea. ${ }^{16,71}$ Hence, the finding that 5-LOX deletion leads to amplified neovascularization indicates an unexpected protective role for this pathway in the immune privileged cornea, which strongly implicates $L_{X A_{4}}$ as the metabolic product. Taken together, our data from 5-LOX KO mice, which are $L X A_{4}$ knockouts, ${ }^{50,51}$ and from 12/15-LOX $\mathrm{KO}$ mice provide strong evidence for endogenous $L X A_{4}$ as a key regulator of inflammatory neovascularization.

Topical treatment with $\mathrm{LXA}_{4}$ initiated immediately after inducing chronic injury not only attenuated formation of blood vessels, but also critical mediators of inflammatory neovascularization, namely VEGF-A and FLT4. In addition, topical $\mathrm{LXA}_{4}$ reduced expression of $\mathrm{HO}-1$, a stress gene and a marker of inflammation, whose degree of expression directly correlates with the degree of the inflammatory response ${ }^{37,72}$ and is a key feature of nonresolving inflammation in the cornea. ${ }^{38}$ Contrary to $\mathrm{LXA}_{4}$, topical 15-HETE exacerbated inflammatory neovascularization (Figure 4), which supports the notion that the protective actions of 15-LOX require metabolism of 15HETE to LXA ${ }_{4}$ by 5-LOX, which is expressed in leukocytes $^{49}$ and the cornea. ${ }^{36}$

The findings that topical $L X A_{4}$ inhibits and in vivo deletion of $\mathrm{LXA}_{4}$ formation exacerbates VEGF-A and FLT4 expression provides a compelling argument for regulation of angiogenic responses by the resident $L X A_{4}$ circuit. It is important to recognize that the VEGF-A circuit, in addition to its role as a key angiogenic factor, is also involved in macrophage chemotaxis, a cell type that not only is a major source but also a target for the bioactions of VEGF-A. VEGF-A induces release of several prominent inflammatory mediators in primary endothelial cells such as interleukins 6 and 8, and tumor necrosis factor $\alpha^{28}$ and was originally identified as a potent vascular permeability factor. ${ }^{73}$ Moreover, local intravitreal injection of VEGF-A leads to local adhesion of leukocytes and monocyte chemotaxis, ${ }^{3}$ while VEGF-A traps significantly inhibit leukocyte infiltration in the suture injury model. ${ }^{16}$ These findings underscore the important role of VEGF-A as a modulator of inflammatory function. Hence, $\mathrm{LXA}_{4}$ 's ability to inhibit VEGF-A up-regulation in response to injury indicates that $\mathrm{LXA}_{4}$ may regulate the early phase of both angiogenic and inflammatory responses. In this context it 
also important to note that our model is inflammatory based neovascularization. Hence, it remains to be determined if our findings regarding the protective actions of the resident $L X A_{4}$ circuit extend to hypoxia-driven angiogenesis.

FLT4 is the endothelial receptor for VEGF-C and VEGF-D and mediates lymphangiogenesis. Recent evidence suggests that FLT4 has a key role in sprouting angiogenesis and thus may drive angiogenesis. ${ }^{12}$ The observation that FLT4 is required for spontaneous hemeangiogenesis in the cornea of corn1 mice ${ }^{11}$ support the notion for a pivotal role in pathological neovascularization. It is of particular interest that a functional FLT4 receptor is expressed in corneal epithelial cells. ${ }^{10}$ How FLT4 ligation and proven kinase activity ${ }^{10}$ regulates epithelial function remains to be defined. What is clear is that chronic injury as early as 48 hours, which is initial phase of angiogenesis, strikingly up-regulates expression of FLT4. Moreover, deletion of protective $L X A_{4}$ biosynthetic pathways correlates with amplified expression FLT4 while topical treatment with $\mathrm{LXA}_{4}$ inhibits it expression (Figure $6,7)$. Detailed studies are required to define the cellular targets for $\mathrm{LXA}_{4}$ in the cornea (ie, FLT4 expressing endothelial cells, epithelial cells and/or macrophages) and if activation of VEGF circuits precedes inflammation or is a consequence of injury-induced inflammation.

Our findings regarding the endogenous role $\mathrm{LXA}_{4}$ in the model of suture induced angiogenesis are in general agreement with a recent report ${ }^{39}$ that assessed the therapeutic actions (subconjunctival injections) of a stable analog of $\mathrm{LXA}_{4}$ and two $\omega-3$ PUFA-derived anti-inflammatory autacoids. However, in regards to FLT4 expression our findings with 12/15-LOX KO mice and direct topical treatment with $\mathrm{LXA}_{4}$ both indicate that FLT4 expression is regulated by exogenous and endogenous $\mathrm{LXA}_{4}$ in the cornea, while the report by Lin and colleagues $^{39}$ shows a strong trend but not significant inhibition in male BALB/c mice. These differences are likely due to differences in the treatment protocols (ie, direct daily t.i.d. corneal treatment versus indirect treatment by subconjunctival injection every 48 hours), the use of a stable $L X A_{4}$ analog versus native $L X A_{4}$ and mouse strain differences (C57BI/6J versus BALB/C).

$A L X$ receptors are expressed in leukocytes, epithelial cells and vascular endothelial cells, hence, LXA 4 can regulate the function of all cell types critical to corneal neovascularization. LXA ${ }_{4}$ 's well-established anti-inflammatory actions with PMN, macrophages, and epithelial cells are consistent with our finding that therapeutic amplification attenuates while in vivo inhibition of endogenous $L X A_{4}$ formation exacerbates chronic inflammation. However, it is important to recognize that $L X A_{4}$ and stable analogs of $L X A_{4}$ have been shown to directly regulate signaling of the VEGF-2 (FLK1) receptor and its expression in endothelial cells. ${ }^{25,26,28}$ Thus, the ability of endogenous and therapeutic $L X A_{4}$ to inhibit inflammatory neovascularization is likely extends to direct regulation of angiogenesis. In this regard, it is important to recognize that angiogenic responses as a consequence of corneal injury do not require leukocyte infiltration since complete depletion of PMN and monocytes attenuates but does not prevent angiogenesis. ${ }^{71}$ Moreover, the initiating signals or cell types for injury-induced angiogenic response have not been elucidated in the cornea. In view of the fact that the healthy cornea, especially the central cornea, contains no leukocytes the initial targets for $L X A_{4}$ are likely epithelial cells, since these cells are a predominant cell source of ALX in human and mouse corneas. ${ }^{15,36}$

In summary, our current results demonstrate that resident $L X A_{4}$ circuits are key determinants for the degree of inflammatory neovascularization in response to chronic injury. Genetic deletion of LXA $\mathrm{A}_{4}$ biosynthetic pathways or amplification with exogenous $L X A_{4}$ provides strong evidence that this protective circuit controls key regulators of the angiogenic and inflammatory response in the cornea. In view of the prominent expression of 15-LOX and the $A L X$ receptor in epithelial cells and macrophages, the endogenous role the $\mathrm{LXA}_{4}$ circuit in pathological angiogenesis clearly warrants further studies.

\section{Acknowledgment}

We thank Dr. Lars Bellner at New York Medical College for skillful and expert help with immunohistochemistry and image analyses of corneal neovascularization in the 15-LOX KO mice and congenic controls.

\section{References}

1. Folkman J: Angiogenesis in cancer, vascular, rheumatoid and other disease. Nat Med 1995, 1:27-31

2. Folkman J: Angiogenesis: an organizing principle for drug discovery? Nat Rev Drug Discov 2007, 6:273-286

3. Costa C, Incio J, Soares R: Angiogenesis and chronic inflammation: cause or consequence? Angiogenesis 2007, 10:149-166

4. Noel A, Jost M, Lambert V, Lecomte J, Rakic JM: Anti-angiogenic therapy of exudative age-related macular degeneration: current progress and emerging concepts. Trends Mol Med 2007, 13:345-352

5. Cao Y, Langer R: A review of Judah Folkman's remarkable achievements in biomedicine. Proc Natl Acad Sci USA 2008;105:13203-13205

6. Gimbrone MA Jr, Cotran RS, Leapman SB, Folkman J: Tumor growth and neovascularization: an experimental model using the rabbit cornea. J Natl Cancer Inst 1974, 52:413-427

7. Streilein JW: Ocular immune privilege: therapeutic opportunities from an experiment of nature. Nat Rev Immunol 2003, 3:879-889

8. Ambati BK, Nozaki M, Singh N, Takeda A, Jani PD, Suthar T, Albuquerque RJ, Richter E, Sakurai E, Newcomb MT, Kleinman ME, Caldwell RB, Lin Q, Ogura Y, Orecchia A, Samuelson DA, Agnew DW, St Leger J, Green WR, Mahasreshti PJ, Curiel DT, Kwan D, Marsh H, Ikeda S, Leiper LJ, Collinson JM, Bogdanovich S, Khurana TS, Shibuya M, Baldwin ME, Ferrara N, Gerber HP, De Falco S, Witta J, Baffi JZ, Raisler BJ, Ambati J: Corneal avascularity is due to soluble VEGF receptor-1. Nature 2006, 443:993-997

9. Chen L, Hamrah P, Cursiefen C, Zhang Q, Pytowski B, Streilein JW Dana MR: Vascular endothelial growth factor receptor-3 mediates induction of corneal alloimmunity. 2004. Ocul Immunol Inflamm 2007, 15:275-278

10. Cursiefen C, Chen L, Saint-Geniez M, Hamrah P, Jin Y, Rashid S, Pytowski B, Persaud K, Wu Y, Streilein JW, Dana R: Nonvascular VEGF receptor 3 expression by corneal epithelium maintains avascularity and vision. Proc Natl Acad Sci USA 2006, 103:11405-11410

11. Cursiefen C, Ikeda S, Nishina PM, Smith RS, Ikeda A, Jackson D, Mo JS, Chen L, Dana MR, Pytowski B, Kruse FE, Streilein JW: Spontaneous corneal hem- and lymphangiogenesis in mice with destrin-mutation depend on VEGFR3 signaling. Am J Pathol 2005, 166:1367-1377

12. Tammela T, Zarkada G, Wallgard E, Murtomaki A, Suchting S, Wirzenius M, Waltari M, Hellstrom M, Schomber T, Peltonen R, Freitas 
C, Duarte A, Isoniemi H, Laakkonen P, Christofori G, Yla-Herttuala S, Shibuya M, Pytowski B, Eichmann A, Betsholtz C, Alitalo K: Blocking VEGFR-3 suppresses angiogenic sprouting and vascular network formation. Nature 2008, 454:656-660

13. Paavonen K, Mandelin J, Partanen T, Jussila L, Li TF, Ristimaki A, Alitalo $\mathrm{K}$, Konttinen $\mathrm{YT}$ : Vascular endothelial growth factors $\mathrm{C}$ and $\mathrm{D}$ and their VEGFR-2 and 3 receptors in blood and lymphatic vessels in healthy and arthritic synovium. J Rheumatol 2002, 29:39-45

14. Kuhn H, O'Donnell VB: Inflammation and immune regulation by $12 /$ 15-lipoxygenases. Prog Lipid Res 2006, 45:334-356

15. Gronert K: Lipoxins in the eye and their role in wound healing Prostaglandins Leukot Essent Fatty Acids 2005, 73:221-229

16. Cursiefen C, Chen L, Borges LP, Jackson D, Cao J, Radziejewski C, D'Amore PA, Dana MR, Wiegand SJ, Streilein JW: VEGF-A stimulates lymphangiogenesis and hemangiogenesis in inflammatory neovascularization via macrophage recruitment. J Clin Invest 2004, 113:1040-1050

17. Nie D, Tang K, Diglio C, Honn KV: Eicosanoid regulation of angiogenesis: role of endothelial arachidonate 12-lipoxygenase. Hemost Thromb Vasc Biol 2000, 95:2304-2311

18. Bannenberg GL, Aliberti J, Hong S, Sher A, Serhan C: Exogenous pathogen and plant 15-lipoxygenase initiate endogenous lipoxin a4 biosynthesis. J Exp Med 2004, 199:515-523

19. Brezinski ME, Serhan CN: Selective incorporation of (15S)-hydroxyeicosatetraenoic acid in phosphatidylinositol of human neutrophils: agonist-induced deacylation and transformation of stored hydroxyeicosanoids. Proc Natl Acad Sci USA 1990, 87:6248-6252

20. Levy BD, Romano M, Chapman HA, Reilly JJ, Drazen J, Serhan CN: Human alveolar macrophages have 15-lipoxygenase and generate 15(S)-hydroxy-5,8,11-cis-13-trans-eicosatetraenoic acid and lipoxins. J Clin Invest 1993, 92:1572-1579

21. Serhan CN, Jain A, Marleau S, Clish C, Kantarci A, Behbehani B, Colgan SP, Stahl GL, Merched A, Petasis NA, Chan L, Van Dyke TE: Reduced inflammation and tissue damage in transgenic rabbits overexpressing 15-lipoxygenase and endogenous anti-inflammatory lipid mediators. J Immunol 2003, 171:6856-6865

22. Levy BD, Clish CB, Schmidt B, Gronert K, Serhan CN: Lipid mediator class switching during acute inflammation: signals in resolution. Nat Immunol 2001, 2:612-619

23. Nassar GM, Morrow JD, Roberts LJ II, Lakkis FG, Badr KF: Induction of 15-lipoxygenase by interleukin-13 in human blood monocytes. J Biol Chem 1994, 269:27631-27634

24. Chavis C, Godard P, Crastes de Paulet A, Damon M: Formation of lipoxins and leukotrienes by human alveolar macrophages incubated with 15(S)-HETE: a model for cellular cooperation between macrophages and airway epithelial cells. Eicosanoids 1992, 5:203-211

25. Cezar-de-Mello PF, Nascimento-Silva V, Villela CG, Fierro IM: Aspirintriggered Lipoxin A4 inhibition of VEGF-induced endothelial cell migration involves actin polymerization and focal adhesion assembly. Oncogene 2006, 25:122-129

26. Cezar-de-Mello PF, Vieira AM, Nascimento-Silva V, Villela CG, BariaFidalgo C, Fierro IM: ATL-1, an analogue of aspirin-triggered lipoxin A4, is a potent inhibitor of several steps in angiogenesis induced by vascular endothelial growth factor. Br J Pharmacol 2008, 153:956-965

27. Fierro IM, Kutok JL, Serhan $\mathrm{CN}$ : Novel lipid mediator regulators of endothelial cell proliferation and migration: aspirin-triggered-15R-lipoxin A(4) and lipoxin A(4). J Pharmacol Exp Ther 2002, 300:385-392

28. Baker N, O'Meara SJ, Scannell M, Maderna P, Godson C: Lipoxin A4: anti-inflammatory and anti-angiogenic impact on endothelial cells. $\mathrm{J}$ Immunol 2009, 182:3819-3826

29. Mochizuki N, Kwon YG: 15-lipoxygenase-1 in the vasculature: expanding roles in angiogenesis. Circ Res 2008, 102:143-145

30. Bajpai AK, Blaskova E, Pakala SB, Zhao T, Glasgow WC, Penn JS, Johnson DA, Rao GN: 15(S)-HETE production in human retinal microvascular endothelial cells by hypoxia: novel role for MEK1 in 15(S)-HETE induced angiogenesis. Invest Ophthalmol Vis Sci 2007, 48:4930-4938

31. Srivastava K, Kundumani-Sridharan V, Zhang B, Bajpai AK, Rao GN: 15(S)-hydroxyeicosatetraenoic acid-induced angiogenesis requires STAT3-dependent expression of VEGF. Cancer Res 2007, 67:4328-4336

32. Viita H, Markkanen J, Eriksson E, Nurminen M, Kinnunen K, Babu M, Heikura T, Turpeinen S, Laidinen S, Takalo T, Yla-Herttuala S: 15lipoxygenase-1 prevents vascular endothelial growth factor $\mathrm{A}$ - and placental growth factor-induced angiogenic effects in rabbit skeletal muscles via reduction in growth factor mRNA levels. NO bioactivity, and downregulation of VEGF receptor 2 expression. Circ Res 2008, 102:177-184

33. Funk CD: Prostaglandins and leukotrienes: advances in eicosanoid biology. Science 2001, 294:1871-1875

34. Funk CD, Chen XS, Johnson EN, Zhao L: Lipoxygenase genes and their targeted disruption. Prostaglandins Other Lipid Mediat 2002, 68-69:303-312

35. Biteman B, Hassan IR, Walker E, Leedom AJ, Dunn M, Seta F, Laniado-Schwartzman M, Gronert K: Interdependence of lipoxin A4 and heme-oxygenase in counter-regulating inflammation during corneal wound healing. FASEB J 2007, 21:2257-2266

36. Gronert K, Maheshwari N, Khan N, Hassan IR, Dunn M, Laniado Schwartzman M: A role for the mouse 12/15-lipoxygenase pathway in promoting epithelial wound healing and host defense. J Biol Chem 2005, 280:15267-15278

37. Hassan IR, Gronert K: Acute changes in dietary omega-3 and omega-6 polyunsaturated fatty acids have a pronounced impact on survival following ischemic renal injury and formation of renoprotective docosahexaenoic acid-derived protectin D1. J Immunol 2009, 182:3223-3232

38. Seta F, Bellner L, Rezzani R, Regan RF, Dunn MW, Abraham NG Gronert K, Laniado-Schwartzman M: Heme oxygenase-2 is a critical determinant for execution of an acute inflammatory and reparative response. Am J Pathol 2006, 169:1612-1623

39. Jin $Y$, Arita M, Zhang Q, Saban DR, Chauhan SK, Chiang N, Serhan CN, Dana R: Novel anti-inflammatory and pro-resolving lipid mediators block inflammatory angiogenesis. Invest Ophthalmol Vis Sci 2009, 50:4743-4752

40. Gronert K, Clish CB, Romano M, Serhan CN: Transcellular regulation of eicosanoid biosynthesis. Methods Mol Biol 1999, 120:119-144

41. Serhan CN, Lu Y, Hong S, Yang R: Mediator lipidomics: search algorithms for eicosanoids, resolvins, and protectins. Methods Enzymol 2007, 432:275-317

42. Murphy RC, Barkley RM, Zemski Berry K, Hankin J, Harrison K, Johnson C, Krank J, McAnoy A, Uhlson C, Zarini S: Electrospray ionization and tandem mass spectrometry of eicosanoids. Anal Biochem 2005, 346:1-42

43. Gonzalez-Periz A, Horrillo R, Ferre N, Gronert K, Dong B, MoranSalvador E, Titos E, Martinez-Clemente M, Lopez-Parra M, Arroyo V. Claria J: Obesity-induced insulin resistance and hepatic steatosis are alleviated by omega-3 fatty acids: a role for resolvins and protectins. FASEB J 2009, 23:1946-1957

44. Chiang N, Takano T, Clish CB, Petasis NA, Tai H-H, Serhan CN: Aspirin-triggered 15-epi-lipoxin $\mathrm{A}_{4}$ (ATL) generation by human leukocytes and murine peritonitis exudates: development of a specific

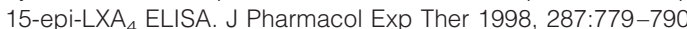

45. Clish CB, Levy BD, Chiang N, Tai HH, Serhan CN: Oxidoreductases in lipoxin A4 metabolic inactivation: a novel role for 15-onoprostaglandin 13-reductase/leukotriene B4 12-hydroxydehydrogenase in inflammation. J Biol Chem 2000, 275:25372-25380

46. Bellner L, Vitto M, Patil KA, Dunn MW, Regan R, Laniado-Schwartzman $M$ : Exacerbated corneal inflammation and neovascularization in the HO-2 null mice is ameliorated by biliverdin. Exp Eye Res 2008, $87: 268-278$

47. Chiang N, Serhan CN, Dahlen SE, Drazen JM, Hay DW, Rovati GE, Shimizu T, Yokomizo T, Brink C: The lipoxin receptor ALX: potent ligand-specific and stereoselective actions in vivo. Pharmacol Rev 2006, 58:463-487

48. Nie D, Honn KV: Eicosanoid regulation of angiogenesis in tumors. Semin Thromb Hemost 2004, 30:119-125

49. Serhan CN, Chiang N, Van Dyke TE: Resolving inflammation: dual anti-inflammatory and pro-resolution lipid mediators. Nat Rev Immunol 2008, 8:349-361

50. Aliberti J, Hieny S, Reis e Sousa C, Serhan CN, Sher A: Lipoxinmediated inhibition of IL-12 production by DCs: a mechanism for regulation of microbial immunity. Nat Immunol 2002, 3:76-82

51. Aliberti J, Serhan C, Sher A: Parasite-induced lipoxin A4 is an endogenous regulator of IL-12 production and immunopathology in Toxoplasma gondii infection. J Exp Med 2002, 196:1253-1262

52. Liminga M, Oliw EH: Studies of lipoxygenases in the epithelium of cultured bovine cornea using an air interface model. Exp Eye Res 2000, 71:57-67

53. Gronert K: Lipid autacoids in inflammation and injury responses: a matter of privilege. Mol Interv 2008, 8:28-35 
54. Devchand PR, Arita M, Hong S, Bannenberg G, Moussignac RL, Gronert K, Serhan CN: Human ALX receptor regulates neutrophil recruitment in transgenic mice: roles in inflammation and host defense. FASEB J 2003, 17:652-659

55. Serhan CN, Brain SD, Buckley CD, Gilroy DW, Haslett C, O'Neill LA, Perretti M, Rossi AG, Wallace JL: Resolution of inflammation: state of the art, definitions and terms. FASEB J 2007, 21:325-332

56. Schwab JM, Chiang N, Arita M, Serhan CN: Resolvin E1 and protectin D1 activate inflammation-resolution programmes. Nature 2007, 447: 869-874

57. Gilroy DW, Lawrence T, Perretti M, Rossi AG: Inflammatory resolution: new opportunities for drug discovery. Nat Rev Drug Discov 2004, 3:401-416

58. Calandria JM, Marcheselli VL, Mukherjee PK, Uddin J, Winkler JW, Petasis NA, Bazan NG: Selective survival rescue in 15-lipoxygenase-1 deficient retinal pigment epithelial cells by the novel docosahexaenoic acid-derived mediator, neuroprotectin D1. J Biol Chem 2009, 284: 17877-17882

59. Serhan CN, Yang R, Martinod K, Kasuga K, Pillai PS, Porter TF, Oh SF, Spite M: Maresins: novel macrophage mediators with potent antiinflammatory and proresolving actions. J Exp Med 2009, 206:15-23

60. Qin Q, Patil KA, Gronert K, Sharma SC: Neuroprotectin D1 inhibits retinal ganglion cell death following axotomy. Prostaglandins Leukot Essent Fatty Acids 2008, 79:201-207

61. Lukiw WJ, Cui JG, Marcheselli VL, Bodker M, Botkjaer A, Gotlinger K, Serhan CN, Bazan NG: A role for docosahexaenoic acid-derived neuroprotectin D1 in neural cell survival and Alzheimer disease. J Clin Invest 2005, 115:2774-2783

62. Connor KM, SanGiovanni JP, Lofqvist C, Aderman CM, Chen J, Higuchi A, Hong S, Pravda EA, Majchrzak S, Carper D, Hellstrom A, Kang JX, Chew EY, Salem N Jr, Serhan CN, Smith LE: Increased dietary intake of omega-3-polyunsaturated fatty acids reduces pathological retinal angiogenesis. Nat Med 2007, 13:868-873
63. Chang MS, Schneider C, Roberts RL, Shappell SB, Haselton FR, Boeglin WE, Brash AR: Detection and subcellular localization of two 15S-lipoxygenases in human cornea. Invest Ophthalmol Vis Sci 2005, 46:849-856

64. Liminga M, Fagerholm P, Oliw EH: Lipoxygenases in corneal epithelia of man and cynomolgus monkey. Exp Eye Res 1994, 59:313-321

65. Munger KA, Montero A, Fukunaga M, Uda S, Yura T, Imai E, Kaneda $\mathrm{Y}$, Valdivielso JM, Badr KF: Transfection of rat kidney with human 15-lipoxygenase suppresses inflammation and preserves function in experimental glomerulonephritis. Proc Natl Acad Sci USA 1999, 96:13375-13380

66. Shen J, Herderick E, Cornhill JF, Zsigmond E, Kim HS, Kuhn H, Guevara NV, Chan L: Macrophage-mediated 15-lipoxygenase expression protects against atherosclerosis development. J Clin Invest 1996, 98:2201-2208

67. Godson C, Brady HR: Lipoxins: novel anti-inflammatory therapeutics? Curr Op Invest Drugs 2000, 1:380-385

68. McMahon B, Mitchell S, Brady HR, Godson C: Lipoxins: revelations on resolution. Trends Pharmacol Sci 2001, 22:391-395

69. Gronert K, Gewirtz A, Madara JL, Serhan CN: Identification of a human enterocyte lipoxin A4 receptor that is regulated by interleukin (IL)-13 and interferon gamma and inhibits tumor necrosis factor alpha-induced IL-8 release. J Exp Med 1998, 187:1285-1294

70. Huang LC, Petkova TD, Reins RY, Proske RJ, McDermott AM: Multifunctional roles of human cathelicidin (LL-37) at the ocular surface. Invest Ophthalmol Vis Sci 2006, 47:2369-2380

71. Sholley MM, Gimbrone MA Jr, Cotran RS: The effects of leukocyte depletion on corneal neovascularization. Lab Invest 1978, 38:32-40

72. Abraham NG, Kappas A: Pharmacological and clinical aspects of heme oxygenase. Pharmacol Rev 2008, 60:79-127

73. Cross MJ, Claesson-Welsh L: FGF and VEGF function in angiogenesis: signalling pathways, biological responses and therapeutic inhibition. Trends Pharmacol Sci 2001, 22:201-220 